06

\title{
Влияние размерных параметров нанокристаллов DAST на их линейные и нелиейно-оптические параметры
}

\author{
(С) Т.Н. Погосян ${ }^{1,2}$, И.Ю. Денисюк ${ }^{1, \uparrow}$, Н.Д. Лай ${ }^{2}$ \\ ${ }^{1}$ Университет ИТМО, \\ 197101 Санкт-Петербург, Россия \\ ${ }^{2}$ ENS Paris-Saclay, \\ 94230 Cachan, France \\ Te-mail: denisiuk@mail.ifmo.ru
}

Поступила в редакцию 10.10.2018 г.

В окончательной редакции 29.11.2018 г.

Принята к публикации 07.12.2018 г.

\begin{abstract}
Проведен синтез нелинейно-оптических нанокристаллов DAST (trans-4'-(dimethylamino)-N-methyl-4stilbazolium tosylate) в матрице из полиметилметакрилата методом зародышеобразования в высыхающей пленке полимера при различных концентрациях растворителя. Получены нанокристаллы с размером, прогрессивно возрастающим от 70 до $2500 \mathrm{~nm}$. Исследованы размерные эффекты нелинейно-оптического коэффициента методом генерации второй гармоники импульсного излучения лазера YAG-Nd $1064 \mathrm{~nm}$. Показано, что уменьшение нелинейно-оптического коэффициента при уменьшении размера не превышает 1.5 раза. Исследованы спектры оптического поглощения и форма нанокристаллов в зависимости от их размеров.
\end{abstract}

DOI: 10.21883/OS.2019.03.47376.299-18

\section{Введение}

В настоящее время нелинейные структуры с фазовой квазисинхронизацией (ФКС) ограничены одномерными и двумерными видами в связи с техническими проблемами реализации трехмерной (3D) структуры. Единственной практической реализацией подобной структуры можно назвать произвольно-ориентированный кристалл $\mathrm{Ba}_{0.77} \mathrm{Ca}_{0.2} 3 \mathrm{TiO}_{3}$ [1]. Согласно работе [2], для формирования 3D нелинейных структур ФКС можно создать полимерный материал с 3D пространственным распределением нелинейных свойств материала. Одной из возможностей реализовать данную идею является формирование трехмерного пространственного распределения субмикронных произвольно-ориентированных нелинейных кристаллов DAST (trans-4'-(dimethylamino)-N-methyl-4stilbazolium tosylate) в толстой пленке полиметилметакрилата (Poly(methyl methacrylate), PMMA) - DAST . молекулярный кристалл с высоким показателем нелинейности [3]. Существует несколько работ, посвященных формированию субмикронных частиц DAST [4,5], и некоторые [6,7] рассматривают синтез частиц в РММА.

\section{Материалы и методы}

В работе использовались растворы DAST (CAS: 80969-52-4 Genolite biotek) в метаноле (322415 Aldrich) и PMMA (Plexiglas $\AA$ V045) в хлороформе (CL0218 Scharlau). После приготовления два раствора смешивались без потери гомогенности. Во всех растворах масса DAST была равна 2\% от массы РММА. Количество метанола рассчитывалось исходя из предела растворимости
DAST в метаноле при комнатной температуре [8]. Концентрация РММА в хлороформе изменялась так, чтобы варьировать вязкость раствора. Были приготовлены 6 растворов с концентрациями компонентов: $1,3,5,8,10$ и $15 \%$ DAST + PMMA.

Пленки были получены методом двухступенчатого центрифугирования (100 rpm и затем $1500 \mathrm{rpm}$ в течение $10 \mathrm{~s})$. Отжиг производился при температуре $180^{\circ} \mathrm{C}$, его длительность варьировалось из-за разницы толщин образцов (см. таблицу). До и после отжига были измерены спектры поглощения с использованием спектрофотометpa PerkinElmer Lambda 950 UV/VIS.

Измерение интенсивности генерации второй гармоники (ГВГ) проводилось с использованием излучения лазера CryLas FDSS 355-300 с длиной волны $1064 \mathrm{~nm}$ и спектрометра Ocean Optics USB2000+. Для измерения размера частиц использовался сканирующий электронный микроскоп (SEM) Hitachi S-3400N. Образцы были подготовлены следующим образом: пленки на подложке были помещены в толуол (34929 Riedel-de Haen), который растворил поверхностный слой РММА. При этом частицы DAST не были повреждены и остались на подложке. Затем образцы были покрыты тонким слоем золота ( $15 \mathrm{~nm})$, и были получены их SEM-изображения, по которым проведено измерение размеров кристаллов.

\section{Результаты и обсуждение}

Пользуясь методом, изложенным в работе [5], мы исследовали влияние вязкости раствора при формировании 


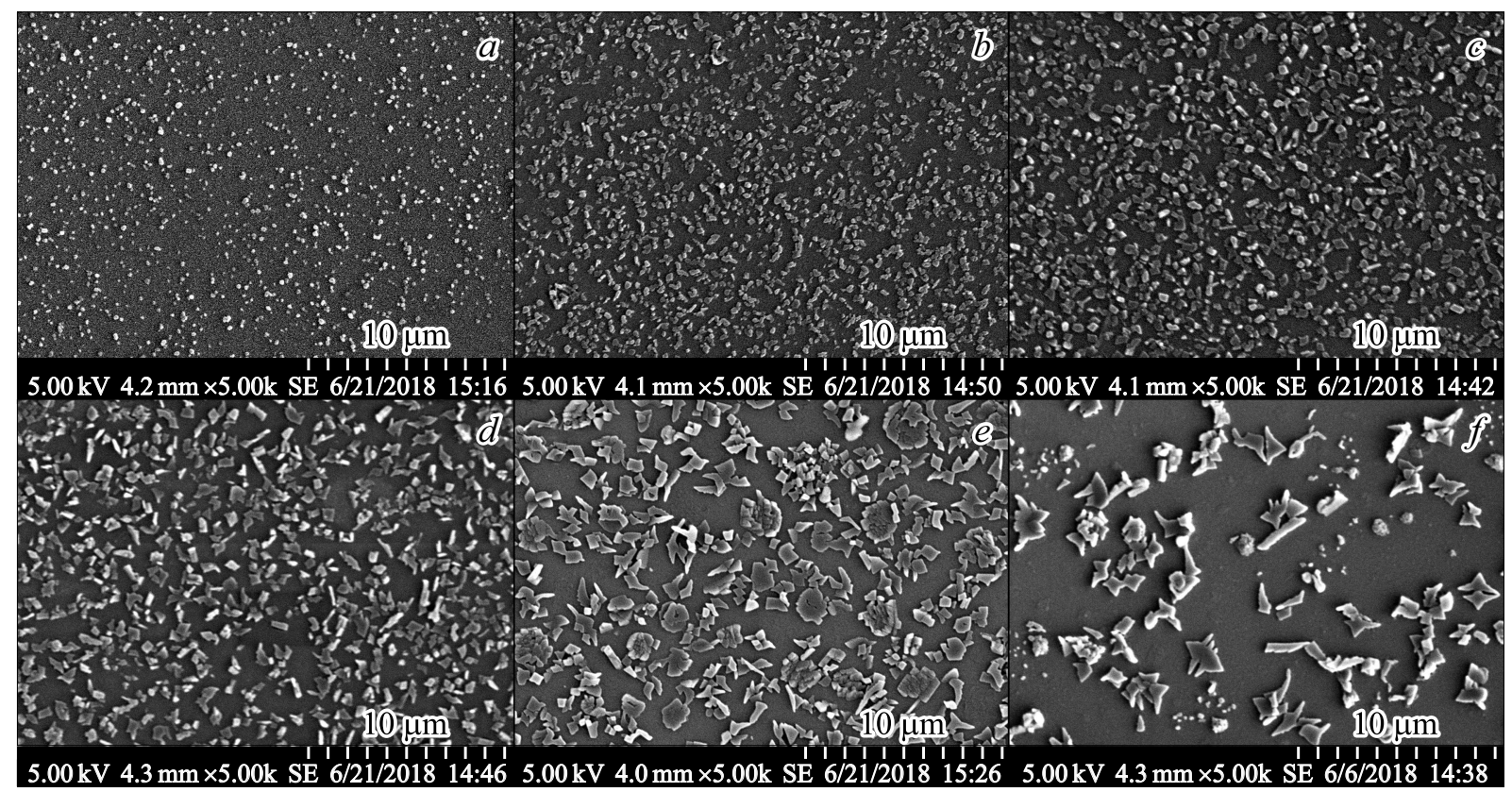

Рис. 1. SEM-изображения образцов, приготовленных из растворов с концентрацией, \%: $(a)$ 1, (b) 3, (c), (d) 8, (e) 10, (f) 15\%.

Сравнительные характеристики образцов с разными концентрациями компонентов в использованном растворе

\begin{tabular}{c|c|c|c|c|c}
\hline $\begin{array}{c}\text { Концентрация } \\
\text { исходного раствора, \% }\end{array}$ & $\begin{array}{c}\text { Толщина } \\
\text { пленки, } \mu \mathrm{m}\end{array}$ & $\begin{array}{c}\text { Время } \\
\text { отжига, min }\end{array}$ & $\begin{array}{c}\text { Размер } \\
\text { частиц, nm }\end{array}$ & $\begin{array}{c}\text { Интенсивность } \\
\text { ГВГ, соunts }\end{array}$ & $\begin{array}{c}\text { Нелинейно-оптический } \\
\text { коэффициент, } \mu \mathrm{m}^{-0.5}\end{array}$ \\
\hline 1 & 0.4 & 10 & $70-150$ & 416 & 32 \\
3 & 0.9 & 15 & $150-250$ & 800 & 30 \\
5 & 1.9 & 30 & $250-400$ & 4456 & 48 \\
8 & 3.4 & 45 & $250-1000$ & 8791 & 51 \\
10 & 5.0 & 80 & $250-1500$ & 13107 & 51 \\
15 & 6.6 & 90 & $250-2500$ & 14672 & 47
\end{tabular}

пленки PMМА на размер образующихся частиц DAST. Поскольку повышение вязкости при нанесении пленок методом центрифугирования приводит к повышению их толщины, в исследовании вязкость и толщина пленки рассматривались как два взаимосвязанных параметра. В основе метода получения нанокристаллов в РММА лежит процесс агрегации молекулярного кристалла в полимерной матрице, при котором размер частиц ограничен транспортом вещества через вязкую среду полимерного раствора. Для PMMA и DAST используются растворители с близкими температурами кипения так, чтобы их испарение происходило с одинаковой скоростью. При этом в начале процесса PMMA и DAST растворены в смеси двух растворителей. Формирование пленки и частиц в ней начинается при центрифугировании и завершается после полного выхода растворителя при отжиге. В процессе быстрого, в течение миллисекунд, выхода растворителя при формировании пленки полимера на центрифуге, достигается состояние, при котором происходит фазовое разделение. В одной фазе находится раствор РММА в хлороформе, а во второй фазе, образу- ющей микропузырьки - раствор DAST в метаноле. Далее быстрый выход метанола приводит к формированию субмикронной частицы DAST в каждом пузырьке. После полного выхода растворителей образуется матрица PMMA с внедренными в нее субмикронными частицами DAST. Поначалу частицы имеют аморфную структуру, которая превращается в кристаллическую в результате термообработки [6].

Очевидно, что толщина пленки влияет на скорость и равномерность испарения растворителей. Поэтому среднее время отжига для более толстых пленок было увеличено, как указано в таблице.

В этой же таблице приведены диапазоны размеров частиц для каждого из образцов. На рис. 1 показаны SEMизображения образцов, снятые в одном масштабе (расстояние между штрихами $10 \mu \mathrm{m})$. Во всех образцах можно обнаружить наночастицы DAST размером от десятков до сотен нанометров, однако при увеличении толщины пленки и времени ее формирования размеры кристаллов увеличиваются, а их форма становится неправильной. В тонких пленках, полученных из растворов с концен- 


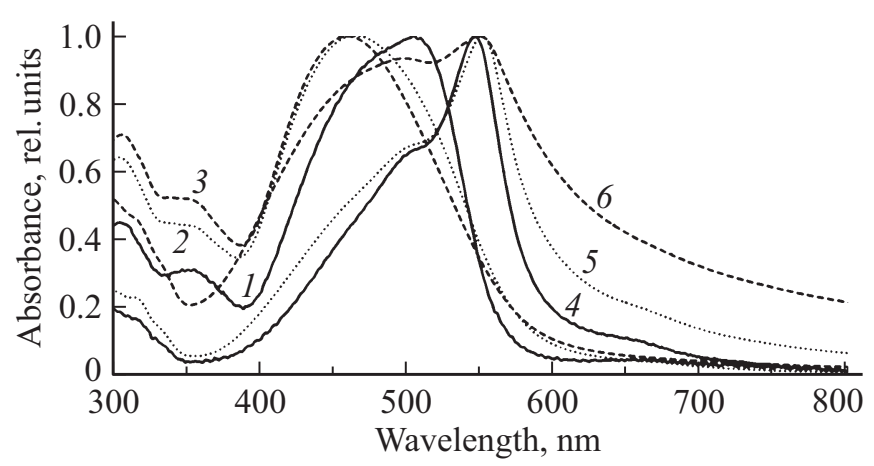

Рис. 2. Спектры поглощения до (1,2 и 3) и после $(4,5$ и 6) отжига для образцов, приготовленных из растворов с концентрацией $1 \%$ (1 и 4, сплошные линии), 5\% (2 и 5 , пунктир) и 15\% (3 и 6, штриховые линии).

трацией 1,3 и 5\%, кристаллы плоские и имеют форму, приближенную к ромбу, что соответствует форме кристалла DAST классической красной конфигурации. Кристаллы в 5\%-ном образце очень схожи с кристаллами, полученными в работе [9]. Разнообразие форм и увеличение размеров кристаллов в толстых пленках, вероятнее всего, обусловлено затруднением испарения растворителей из объема пленки, в результате чего происходит активная диффузия пузырьков метанола с DAST и их слияние. Следует отметить, что в некоторых местах образца, изготовленного из раствора с концентрацией $15 \%$, были обнаружены крупные плоские кристаллы сложной формы, которые, вероятно, образовались из-за движения пузырьков метанола с DAST вдоль подложки под толщей отвердевшей пленки РММА.

Нелинейно-оптический коэффициент был рассчитан как корень квадратный из отношения интенсивности ГВГ к толщине пленки. Из приведенного оценочного расчета видно, что зависимость нелинейно-оптического коэффициента от размера кристаллов незначительна и его величина для наноразмерных кристаллов уменьшается не более чем в 1.5 раза относительно кристаллов размером в единицы микрон.

Уменьшение нелинейно-оптического коэффициента нанометровых кристаллов относительно кристаллов размером в единицы микрометров является новым, ранее не публиковавшимся эффектом, который противоположен эффекту повышения нелинейно-оптического коэффициента при уменьшении толщины кристалла от 500 до $1 \mu \mathrm{m}$ [10]. По нашему мнению, при уменьшении размера от миллиметров до единиц микрометров кристалл делается более однородным, теряет двойникование и нелинейно-оптический коэффициент повышается. При дальнейшем уменьшении размеров, как в нашем исследовании, до десятков нанометров, может сказываться поверхностное разупорядочение молекул, приводящее к падению нелинейного коэффициента.

На этапе до и после отжига были измерены спектры поглощения всех образцов, чтобы подтвердить форми- рование красной кристаллической формы DAST, являющейся нецентросимметричной и обладающей нелинейными свойствами. На рис. 2 представлены спектры поглощения до и после отжига для образцов, полученных из растворов с концентрацией РММА в хлороформе 1, 5 и $15 \%$.

В спектрах всех образцов наблюдалось появление кристаллического максимума около $550 \mathrm{~nm}$, который характерен для нужной нам кристаллической формы DAST. Характерно, что до отжига пленки имели желтоватый цвет, и более толстые пленки имели меньшую прозрачность. Однако после отжига пленки приобрели розоватый цвет, а толстые пленки стали прозрачнее. При повышении толщины пленок и увеличении размера кристаллов относительная величина кристаллического максимума несколько возрастает, приближаясь к форме спектра, характерной для крупных кристаллов, исследованных в работе [11].

\section{Вывод}

В настоящей работе определена зависимость нелинейно-оптического коэффициента нанокомпозита с кристаллами DAST от размера кристаллов в диапазоне $100 \mathrm{~nm}-2.0 \mu \mathrm{m}$. Показано, что увеличение размера кристаллов незначительно - не более чем в 1.5 раза увеличивает коэффициент нелинейности материала. В то же время увеличение кристалла от 100 до $300 \mathrm{~nm}$ приводит к изменению спектра в направлении формы спектра, характерной для крупного кристалла. При дальнейшем увеличении размеров форма спектра не изменяется, а кристаллы приобретают неправильную, хаотически искривленную форму, что свидетельствует о нарушении процесса их роста. Рассмотренный способ формирования нелинейно-оптических кристаллов минимальных размеров, на уровне $100 \mathrm{~nm}$ и менее, можно использовать для создания $2 \mathrm{D}$ и $3 \mathrm{D}$ нелинейно-оптических решеток.

Работа выполнена при поддержке по гранту Российского фонда фундаментальных исследований РФФИ (проект № 18-52-16014).

\section{Список литературы}

[1] Xu T., Lu D., Yu H., Zhang H., Zhang Y., Wang J. // Appl. Phys. Lett. 2016. V. 108. P. 051907.

[2] Pogosian T., Lai N.D. // Phys. Rev. A. 2016. V. 94. P. 063821.

[3] Pan F., Knöpfle G., Bosshard Ch., Follonier S., Spreiter R., Wong M.S., Günter P. // Appl. Phys. Lett. 1996. V. 69. N 1. P. 13.

[4] Kaneko Y., Shimada S., Fukuda T., Kimura T., Yokoi H., Matsuda H., Onodera T., Kasai H., Okada S., Oikawa H., Nakan H. // Adv. Mater. 2005. V. 17. N 2 P. 160.

[5] Zheng M.L., Chen W.Q., Fujita K., Duan X.M., Kawata S. // Nanoscale. 2010. V. 2. P. 913.

[6] Burunkova J.A., Denisyuk I.Yu., Fokina M.I. // Mol. Cryst. Liq. Crys. 2014. V. 589. P. 178. 
[7] Macchi R., Cariati E., Marinotto D., Roberto D., Tordin E., Ugo R., Bozio R., Cozzuol M., Pedron D., Mattei G. // J. Mater. Chem. 2010. V. 20. P. 1885.

[8] Thomas T., Ramaclus J.V., Mena F.P., Mosquera E., Sagayaraja P., Michaelb E.A. // Cryst. Eng. Commun. 2015. V. 17. P. 1989.

[9] Kasai H., Kaneko Y., Onodera, Nakanishi H., Oikawa H., Okada S., Shimada S., Kimura T., Matsuda H. // Proc. SPIE. 2008. V. 6891. P. 689114.

[10] Geis W., Sinta R., Mowers W., Deneault S.J., Marchant M.F., Krohn K.E., Spector S.J., Calawa D.R., Lyszczarz T.M. // Appl. Phys. Lett. 2004. V. 84 P. 3729.

[11] Bhowmik A.K., Xu J., Thakur M. // Appl. Phys. Lett. 1999. V. 75 N 21. P. 3291. 